\title{
New Thiophene Monolayer-Protected Copper Nanoparticles: Synthesis and Chemical-Physical Characterization
}

\author{
Elisabetta Foresti, ${ }^{1}$ Guido Fracasso, ${ }^{1}$ Massimiliano Lanzi, ${ }^{2}$ Isidoro Giorgio Lesci, ${ }^{1}$ \\ Luisa Paganin, ${ }^{2}$ Tommaso Zuccheri, ${ }^{1}$ and Norberto Roveri ${ }^{1}$ \\ ${ }^{1}$ Dipartimento di Chimica "G. Ciamician”, Università di Bologna, Via Selmi 2, 40126 Bologna, Italy \\ ${ }^{2}$ Dipartimento di Chimica Industriale e dei Materiali, Università di Bologna, Viale Risorgimento 4, 40136 Bologna, Italy
}

Correspondence should be addressed to Norberto Roveri, norberto.roveri@unibo.it

Received 29 April 2008; Accepted 31 August 2008

Recommended by Fahrettin Yakuphanoglu

For the first time copper 3-(6-mercaptohexyl)thiophene-protected nanoparticles ( $\mathrm{Cu}$ T6SH) have been synthesized by a onephase system, utilizing an $\mathrm{NaBH}_{4} / \mathrm{LiCl}$ mixture in diglyme as the reducing reagent and avoiding water medium dissolving copper salts. The prepared nanoclusters, characterized by transmission electron microscopy (TEM), have shown a constant spherical morphology with a size dimension of $5-6 \mathrm{~nm}$ in diameter. After their synthesis, no morphological evolution and irreversible aggregation process has been observed after a storage in $\mathrm{CH}_{2} \mathrm{Cl}_{2}$ at low temperature for a period up to six months long. Cu T6SH nanoparticles have been investigated by UV-Visible (UV-Vis) and Fourier transmission infrared (FTIR) spectroscopes to characterize the alkylthiophenes monolayer conformations and the particles optoelectronic properties. The UV-Vis reveals the lack of the surface plasmonic band, previously observed in Cu-nanosized clusters at about 556-570 nm, and shows a wide-band centered at $293 \mathrm{~nm}$, probably due to the high-conformational surface ordering of thiophene rings on the Cu core. The results highlight the importance of the modifications ported to the well-known one-phase synthetic reactions to obtain a clear lack, even after a storage of six months, of any irreversible aggregation that has always characterized chain thiophene-protected metallic nanoparticles.

Copyright (C) 2008 Elisabetta Foresti et al. This is an open access article distributed under the Creative Commons Attribution License, which permits unrestricted use, distribution, and reproduction in any medium, provided the original work is properly cited.

\section{INTRODUCTION}

The properties of materials, which can be tailored by controlling their size and morphology, recently have been engineered by nanotechnology [1]. Nanostructured and nanosized materials have allowed recently innovated technological applications in catalysis [2, 3], biomedical [4], optic, photoresponsive, and electronic devices [5]. Nanoparticles are very interesting for the quantum effect by which their properties are tunable by the particle nanosize and surface chemical-physical characteristics [6]. Nanoparticle science and technology have received an important advancement by Schmid et al., they formerly synthesized ligand-stabilized gold nanoparticles [7] opening the right way to Brust et al. [8] to prepare monolayer-protected gold nanoparticles [8]. The organic monolayers on the surface of metal nanoparticles prevent aggregation and oxidation [9]. Many organic compounds with reactive head groups, such as thiol
[10], sulphide [11], thiosulfate [12], xanthate [13], amine [14], selenide [15], and isocyanide [16], have been utilized to protect by self-assembly different metal nanoparticles including $\mathrm{Au}$ [10-16], Ag [13], Cu [13, 17], Pt [18], Pd [19], Ni [20], and bimetallics [21]. The synthesis of metal nanoparticles protected with various monolayers containing different reactive head and functional tail groups is of high significance to improve their chemical and biochemical technological applications. Because of the expected marked electronic and optical properties of copper nanoparticles, there has been an increased interest in the preparation of stable monolayer-protected copper nanoparticles. Alkyl xanthates [13], alkylamines [22], tetraalkyl ammonium complexes [23], and alkanethiols [17, 24] ligands have been utilized to protect copper nanoparticles. However, a limited progress has been obtained because of the high instability of copper nanoparticles. In order to contrast copper nanoparticles, irreversible aggregation and oxidation, Chen and 
Sommers [17] have prepared copper nanoparticles protected by alkanethiolate in one-phase system. Their prepared spherical (1-2 nm in diameter) $\mathrm{Cu}$ particle bound hexanethiolate monolayers undergo to the oxidation of copper core, morphological evolution, and irreversible aggregation process. Long-chain alkanethiols, which have been found to selfassemble into compact monolayers (i.e., three-dimensional self-assembled monolayers) on metallic nanoparticles [25, 26], cannot only induce metallic nanoparticles to be readily isolated, but also reduce their conductivity. The aim of this study is to synthesize 3-(6-mercaptohexyl)thiopheneprotected copper nanoparticles which, in absence of longchain alkanethiols and in absence of irreversible aggregation, could represent new high-conductive metallic nanoparticles with improved potentialities of tuning their optical and electronic properties.

\section{EXPERIMENTAL SECTION}

\subsection{Chemicals}

Copper chloride $\left(\mathrm{CuCl}_{2}\right.$, Sigma Aldrich, Milano, Italy), 1butanethiol $\left(\mathrm{C}_{4} \mathrm{H}_{9} \mathrm{SH}, 97,0 \%\right.$, Fluka), sodium borohydride $\left(\mathrm{NaBH}_{4}, 99 \%\right.$, Aldrich), lithium chloride (LiCl, 98\%, Fluka) were used as received. The solvents were purchased from Fluka (diethyl ether), Riedel de Haen (tetrahydrofuran, THF), and Acros (2-methoxyetylether 99\%, diglyme) and used as received. $\mathrm{M} \Omega$ ).

Water was supplied by a Millipore A 10 system (18.50

\subsection{Synthesis of 3-(6-mercaptohexyl)thiophene}

The prepara-tion of the monomer 3-(6-mercaptohexyl)thiophene has been performed according to the guidelines described by Ahn et al. [27]. $1.65 \mathrm{~g}$ (6.67 mmol) of 3-(6bromohexyl)thiophene were added to a solution of $0.61 \mathrm{~g}$ $(8.00 \mathrm{mmol})$ of thiourea dissolved in $36 \mathrm{~mL}$ of anhydrous ethanol. The reaction was refluxed for 3 hours under stirring and in inert atmosphere. $0.46 \mathrm{~g}(11.10 \mathrm{mmol})$ of $\mathrm{NaOH}$ dissolved in $15 \mathrm{~mL}$ of distilled water were then added and, after refluxing for 1 hour, the reaction mixture was poured into $150 \mathrm{~mL}$ of an aqueous solution of $\mathrm{HCl}$ $(\mathrm{pH}=4)$ and extracted several times with diethyl ether. The collected organic phases were washed with distilled water, dried over $\mathrm{MgSO}_{4}$, and after evaporation of the solvent at reduced pressure $1.25 \mathrm{~g}(6.24 \mathrm{mmol})$ of crude monomer were obtained ( $94 \%$ yield). The latter was then purified by column chromatography (silica gel; $n$-heptane/ $\mathrm{CHCl}_{3}$ $8: 2)$ giving $1.09 \mathrm{~g}(5.45 \mathrm{mmol})$ of pure monomer $(82 \%$ yield). ${ }^{1} \mathrm{H}$ and ${ }^{13} \mathrm{C}-\mathrm{NMR}$ were run on a Varian Gemini 300 FT-NMR spectrometer $(300 \mathrm{MHz})$ using TMS as reference. Mass spectrometry (MS) was carried out on a VG7070E spectrometer at $70 \mathrm{eV}$.

${ }^{1} \mathrm{H}-\mathrm{NMR}\left(\mathrm{CDCl}_{3}, \mathrm{ppm}\right): \delta 7.22(\mathrm{~m}, 1 \mathrm{H}), 6.98(\mathrm{~m}, 2 \mathrm{H})$, $2.62(\mathrm{t}, 2 \mathrm{H}), 2,50(\mathrm{t}, 2 \mathrm{H}), 1.60(\mathrm{~m}, 4 \mathrm{H}), 1.40(\mathrm{~m}, 4 \mathrm{H})$.

${ }^{13} \mathrm{C}-\mathrm{NMR}\left(\mathrm{CDCl}_{3}, \mathrm{ppm}\right): \delta 143.71,128.92,125.78$, $120.52,32.83,31.09,30.87,30.30,29.57,29.40$.
FT-IR-ATR (Ge crystal): 3102, 3050, 2928, 2855, 2673 (-SH), 1537, 1462, 1439, 1410, 1293, 1279, 1264, 1238, 1152, $1079,939,856,833,771,684,661,633,595,577 \mathrm{~cm}^{-1}$.

Mass (m/z, relative intensity): $200\left(11.4, \mathrm{M}^{+}\right), 98(100.0$, $\left.\mathrm{C}_{5} \mathrm{H}_{6} \mathrm{~S}^{+}\right)$.

\subsection{Synthesis of 3-(6-mercaptohexyl)thiophene monolayer-coated copper nanoparticles}

The particles were synthesized according to a modification of the one-phase system method of Chen and Sommers [17], avoiding any aqueous solvent during the nanoparticles formation.

In a round-bottomed flask $0.24 \mathrm{mmol}(41 \mathrm{mg})$ of $\mathrm{CuCl}_{2}$ dissolved in $20 \mathrm{~mL}$ of tetrahydrofuran (THF) were dropped in $0.71 \mathrm{mmol}$ (143 mg) of 3-(6-mercaptohexyl)thiophene (T6SH) under stirring until the solution remained transparent becoming yellowish. In this solution, 247 $\mathrm{mg}$ of $\mathrm{NaBH}_{4} / \mathrm{LiCl}$ mixture (2/3 molar ratio- $92 \mathrm{mg}$ $\mathrm{NaBH}_{4} / 155 \mathrm{mg} \mathrm{LiCl}$ ) suspended in $40 \mathrm{~mL}$ of diglyme $\left(\mathrm{CH}_{3} \mathrm{OCH}_{2} \mathrm{CH}_{2}\right)_{2} \mathrm{O}$ were dropped under stirring. The rapid turn of solution to dark brown reveals the 3(6-mercaptohexyl)thiophene-coated $\mathrm{Cu}$ nanoparticles formation. Diethyl ether $(150 \mathrm{~mL})$ was added to the reaction mixture before the coated nanoparticles extraction with an $\mathrm{NaCl}$ saturated solution. The extraction was performed using $300 \mathrm{~mL}$ of saline solution and was repeated three times. The diethyl ether solvent was removed under reduced pressure. The dark brownish precipitate was washed twice with cooled methanol and was then separated by centrifugation at $3000 \mathrm{rpm}$.

\subsection{Morphological characterization}

Transmission electron microscopy (TEM) investigations were carried out using a Philips CM 100 electron microscope at an accelerating voltage of $100 \mathrm{kV}$. The powdered samples were ultrasonically dispersed in ultrapure water and then deposited by dropcasting on conventional Formvar/Carbon 200 mesh copper microgrids.

\subsection{Spectroscopic characterization}

FTIR spectra were collected with a Thermo Nicolet FTIR 380 spectrometer equipped with ATR accessory and the spectra resolution was $4 \mathrm{~cm}^{-1}$. The spectrum of the capping agent 3-(6-mercaptohexyl)thiophene was obtained by dropcasting the monomer thiophene onto germanium crystal and the spectrum of the $\mathrm{Cu}$ thiophene-capped nanoparticles was acquired by placing an aliquot of 5-10 mg onto germanium crystal without any additional sample preparation. The spectra were the result of 32 scans.

UV-Vis spectroscopy has been carried out using a Varian Cary 300 Bio spectrophotometer with a $1 \mathrm{~cm}$ quartz cuvette. Solutions of $\mathrm{Cu}$ T6SH nanoparticles were prepared at concentration of $0.1 \mathrm{mg} / \mathrm{mL}$ in dichloromethane $\left(\mathrm{CH}_{2} \mathrm{Cl}_{2}\right)$. 


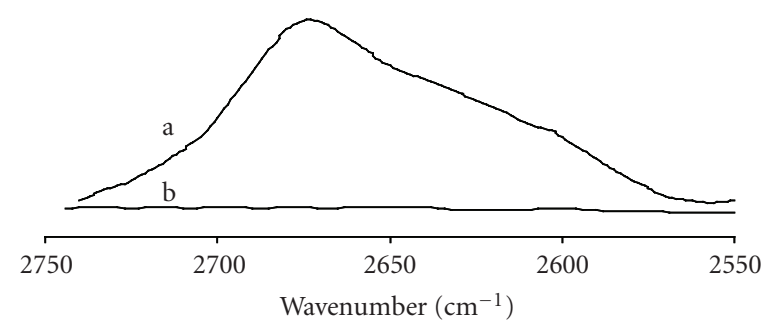

Figure 1: Comparison of the infrared spectra in the range from 2750 to $2550 \mathrm{~cm}^{-1}$ of the free thiophene (a) and $\mathrm{Cu}$ T6SH-protected nanoparticles (b).

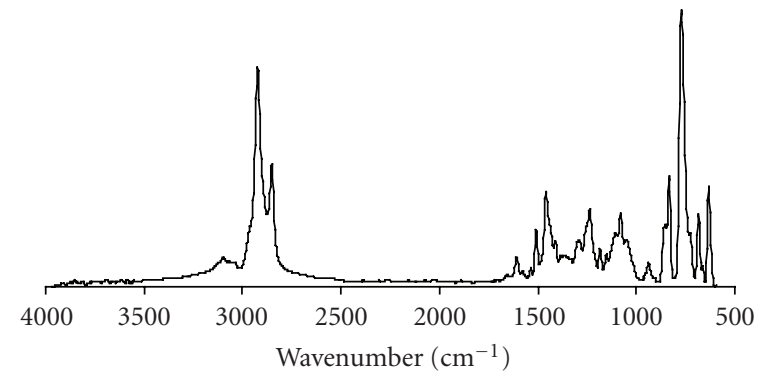

Figure 2: Infrared spectrum of Cu T6SH-protected nanoparticles.

\section{RESULTS AND DISCUSSION}

3-(6-bromohexyl)thiophene was first synthesized as previously described [28] and reacted with thiourea giving 3-(6-mercaptohexyl)thiophene (MDT) with a good yield. Monolayer-protected $\mathrm{Cu}$ nanoparticles were prepared in one-phase system by modified Brust reaction [8] using as reducing reagent a mixture of finely grounded $\mathrm{LiCl}$ and $\mathrm{NaBH}_{4}$ (3/2 molar ratio) suspended in diglyme $\left(\mathrm{CH}_{3} \mathrm{OCH}_{2} \mathrm{CH}_{2}\right)_{2} \mathrm{O}$, instead of $\mathrm{LiBH}_{4}$ (super hydride) dissolved in tetrahydrofuran (THF) according to Chen and Sommers (2001) [17]. These authors have dissolved $\mathrm{Cu}\left(\mathrm{NO}_{3}\right)_{2}$ in water-THF mixture, while we have used pure THF to suspend $\mathrm{CuCl}_{2} \cdot 2 \cdot \mathrm{H}_{2} \mathrm{O}$, in order to avoid any oxidation process and enhance the $\mathrm{LiBH}_{4}$ reducing capacity. Furthermore, diglyme acts not only as chelating agent of the $\mathrm{Li}$ cations, but also as dissolvent. The MDT/ $\mathrm{CuCl}_{2} \cdot 2 \cdot \mathrm{H}_{2} \mathrm{O}$ reactants ratio was 3:1.

\subsection{Spectroscopic studies}

The conformational structure of the Cu particle-organic surfactant monolayer has been examined by FTIR spectroscopy. In Figure 1, infrared spectra in the range of $2750 \mathrm{~cm}^{-1}$ and $2550 \mathrm{~cm}^{-1}$ of the free thiophene (a) and Cu thiophene on protected nanoparticles (b) are compared. The lack of the SH stretching of the free ligand at about $2580 \mathrm{~cm}^{-1}$ is due to the chemisorptions on the $\mathrm{Cu}$ nanoparticles. The $\mathrm{CH}_{2}$ antisymmetric $\left(\mathrm{d}^{-}\right)$and symmetric $\left(\mathrm{d}^{+}\right)$stretching recorded for thiophene ligand have been repeatedly used as a sensitive diagnostic indicator for the conformational ordering of the metal-linked alkyl chains [29-31]. In fact, these two characteristic vibrational stretching modes for the

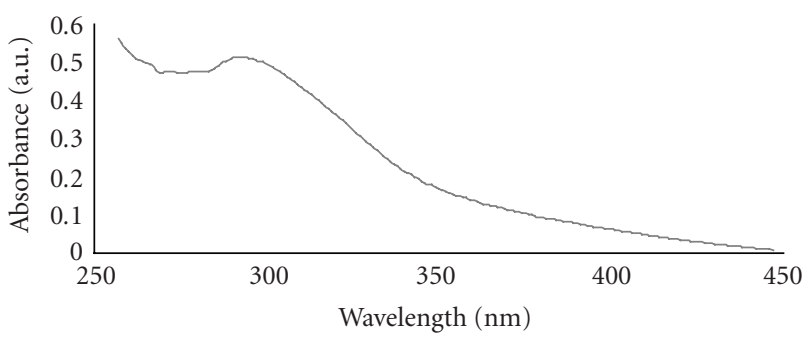

FIgURE 3: UV-Vis spectrum of the $\mathrm{Cu}$ T6SH-protected nanoparticles dissolved in $\mathrm{CH}_{2} \mathrm{Cl}_{2}$.

3-(6-mercaptohexyl)thiophene have been found at 2928 and $2856 \mathrm{~cm}^{-1}$ in solution $[17,32,33]$, while in crystalline state, for all zigzag trans ordered conformations the $v_{\text {as }}\left(\mathrm{d}^{-}\right)$and $v_{\mathrm{s}}\left(\mathrm{d}^{+}\right)$are usually found at 2920 and $2850 \mathrm{~cm}^{-1}$, respectively [20]. The lyophilized $\mathrm{Cu}$ thiophene-protected nanoparticles FTIR spectrum reported in Figure 2 shows the characteristic $v_{\text {as }}\left(\mathrm{d}^{-}\right)$and $v_{\mathrm{s}}\left(\mathrm{d}^{+}\right)$vibrational stretching modes of $\mathrm{CH}_{2}$ at $2924 \mathrm{~cm}^{-1}$ and at $2852 \mathrm{~cm}^{-1}$, respectively, revealing a marked shift toward lower wave numbers than those recorded for the free thiophene ligand. This finding highlights that the capping agent for synthesized $\mathrm{Cu} \mathrm{T} 6 \mathrm{SH}$ has an enhanced ordered structure close to the $\mathrm{Cu}$ cluster surface [32]. The FTIR spectrum reported in Figure [2] has been obtained for $\mathrm{Cu}$ T6SH particles immediately after synthesis, but it does not differ appreciably from the FTIR spectra recorded for the same $\mathrm{Cu}$ thiophene-protected nanoparticles after a long period of storage at low temperature $\left(+4^{\circ} \mathrm{C}\right)$, suspended in $\mathrm{CH}_{2} \mathrm{Cl}_{2}$ up to six months long.

Usually, the optical properties of alkanethiolate-capped transition-metal nanoparticles analyzed by UV-Vis characterization display the presence of a remarkable surface plasmon band (SP) having an intensity and an energy that are strongly dependent on the size and the chemical composition of the system we are studying. The typical absorption peak of the characteristic surface plasmon $\mathrm{Cu}$-nanosized cluster is expected at about $556 \mathrm{~nm} \mathrm{[21],566} \mathrm{nm} \mathrm{[17],} \mathrm{and}$ $570 \mathrm{~nm}[33,34]$. On the contrary, a UV-Vis absorption profiles exhibiting an exponential decay Mie scattering [35] with decreasing photon energy, without the surface-plasmon band, is a characteristic of nanosized particles and has been observed for a copper very small core size diameter of the particles $(<2 \mathrm{~nm})[17,36]$. The spectrum of the $\mathrm{Cu} \mathrm{T} 6 \mathrm{SH}$ particles, reported in Figure 3, does not reveal any evidence of the surface plasmonic band at about $556-570 \mathrm{~nm}$, but shows only a wideband centered at $293 \mathrm{~nm}$ due according to Mie's theory is the summation of all electronic and magnetic multipole oscillations, contributing to the absorption and scattering of the interacting electromagnetic field [37]. A comparable adsorption band at about $340 \mathrm{~nm}$ has been observed for dodecanethiol-protected $\mathrm{Cu}$ nanoclusters of about $3 \mathrm{~nm}$ in diameter [21]. The lowest position of the band at $293 \mathrm{~nm}$, never observed before also for $<2 \mathrm{~nm}$ sized nanoparticles, could be attributed to the shorter (C6) alkyl chain of thiophene ring surface ordered on the $\mathrm{Cu}$ core. Furthermore, a possible interaction between the thiophene 

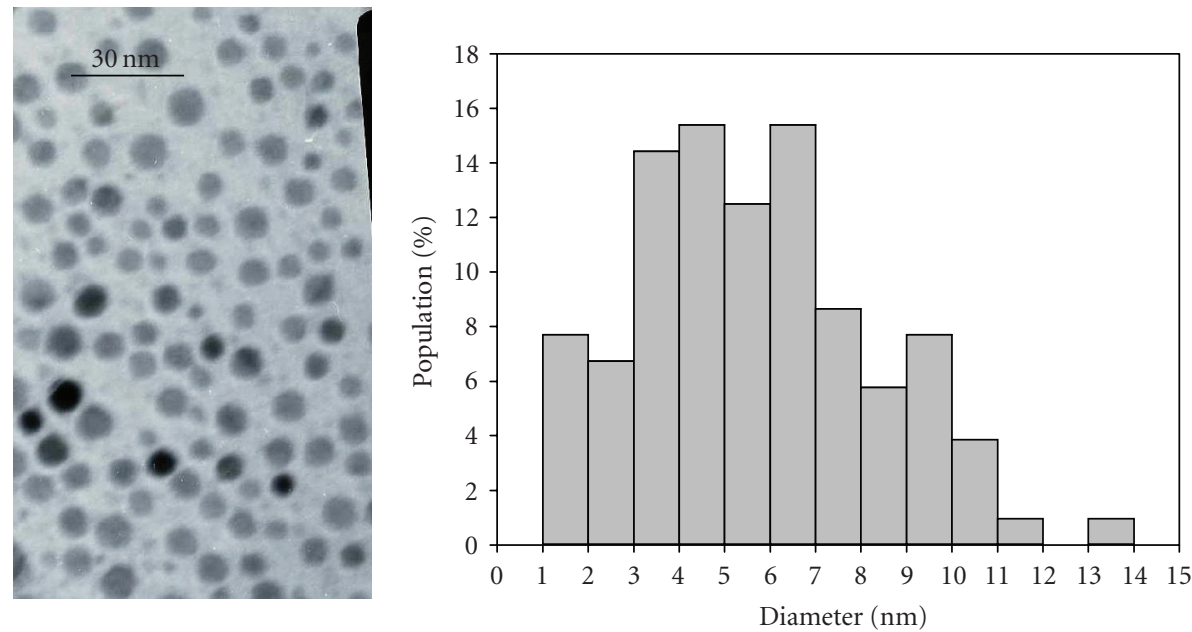

(a)

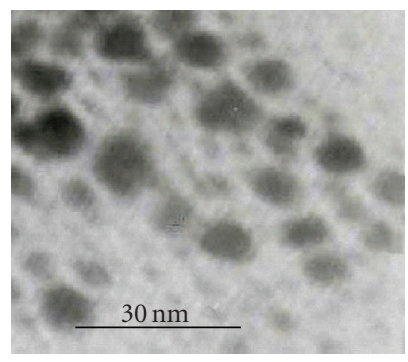

(b)

FIGURE 4: TEM image (a) of the fresh $\mathrm{Cu}$ T6SH nanoparticles synthesized by (Li diglyme) $\mathrm{BH}_{4}$ as a reducing agent and the depict of the nanoparticle size histogram is reported. (b) TEM image of the $\mathrm{Cu}$ T6SH nanoparticles synthesized by (Li diglyme) $\mathrm{BH}_{4}$ as a reducing agent after a period of six months long of storage at low temperature $\left(+4^{\circ} \mathrm{C}\right)$ were suspended in $\mathrm{CH}_{2} \mathrm{Cl}_{2}$ after their synthesis.

rings and the metallic core cannot be left out considering the short alkyl chain length.

After a storing period of six months long, the same $\mathrm{Cu}$ T6SH particles exhibit a UV-Vis absorption profile very close to that previously recorded for fresh nanoparticles, but reveal a slight decrease to $291 \mathrm{~nm}$ of the adsorption band. This data support $s$ the lack of irreversible aggregation previously observed for metallic thiophene-protected nanoparticles [17].

\subsection{Transmission electron microscopic investigation}

TEM has been utilized in investigating the $\mathrm{Cu}$ T6SH particles dimension. Figure 4(a) shows a TEM image of the $\mathrm{Cu}$ T6SH nanoparticles recorded after a period up to six months long of storage at low temperature $\left(+4^{\circ} \mathrm{C}\right)$ suspended in $\mathrm{CH}_{2} \mathrm{Cl}_{2}$ after their synthesis. Nanoparticles exhibit spherical shape while particle size histogram inserted in Figure 4(a) puts in evidence that the median size is $5.65 \mathrm{~nm}$ in diameter. The $\mathrm{Cu}$ T6SH nanoparticles shape is homogenously spherical without exhibiting the irregular shapes and the well-defined faceted morphologies observed for other polythiophenecoated transition-metal nanoparticles [38] and especially for copper nanoparticles dodecanethiol protected [17, 21]. The Cu T6SH nanoparticles morphology and dimensions observed immediately after synthesis (Figure 4(b)) were appreciably unchanged after six months of storage at low temperature $\left(+4^{\circ} \mathrm{C}\right)$ and suspended in $\mathrm{CH}_{2} \mathrm{Cl}_{2}$ after their synthesis. This finding reveals the absence of irreversible nanoparticles aggregation reported for long-chain alkanethiols capped metallic nanoparticles [17].

This result is due to the modifications produced to the one-phase synthetic process of alkanethiolate-protected copper nanoparticles [17] which undergo to the oxidation of copper core, morphological evolution, and irreversible aggregation process.

\section{CONCLUSIONS}

Copper 3-(6-mercaptohexyl)thiophene-protected nanoparticles have been synthesized in a one-phase system by a modified Brust reaction [8] utilizing an $\mathrm{NaBH}_{4} / \mathrm{LiCl}$ mixture in diglyme as the reducing reagent and avoiding water medium in dissolving copper salts. TEM investigation carried out on the $\mathrm{Cu}$ T6SH nanoparticles immediately after synthesis and after different periods up to six months long of storage at low temperature has put in evidence that their spherical shape of about 5-6 nm in diameter does not vary appreciably. The same invariability related to the storage period has been observed for the $\mathrm{Cu}$ T6SH nanoparticles by FTIR and UV- 
Vis spectroscopic characterizations. The characteristic FTIR adsorption bands related to $\nu_{\text {as }}\left(\mathrm{d}^{-}\right)$and $\nu_{\mathrm{s}}\left(\mathrm{d}^{+}\right)$vibrational stretching modes of $\mathrm{CH}_{2}$ have been recorded for synthesized $\mathrm{Cu} \mathrm{T} 6 \mathrm{SH}$ at lower wave numbers than those recorded for the free thiophene ligand, revealing an enhanced ordered structure for the capping agent.

The UV-Vis spectrum of the $\mathrm{Cu}$ T6SH nanoparticles does not reveal any evidence of the surface plasmonic band previously observed in $\mathrm{Cu}$-nanosized clusters at about 556$570 \mathrm{~nm}$, but shows only a wideband centered at $293 \mathrm{~nm}$ probably due to the shorter (C6) alkyl chain of thiophene ring surface ordered on the $\mathrm{Cu}$ core.

TEM, FTIR, and UV-Vis results have pointed out the lack of irreversible aggregation previously observed for long-chain thiophene-protected metallic nanoparticles [17] revealing the importance of the modifications ported to the well-known one-phase synthetic Brust reaction [8]. The presence of short-chain alkanethiols around the metallic core and the observed absence of irreversible aggregation could improve their conductivity and potentialities of tuning their optical and electronic properties which are under investigation.

\section{ACKNOWLEDGMENTS}

The authors would like to acknowledge financial support from the University of Bologna, CIRCMSB, and the Italian Ministero dell'Istruzione, Università e Ricerca (MIUR), PRIN Project no. 2006032335.

\section{REFERENCES}

[1] Y. -S. Shon, "Metal nanoparticles protected with monolayers: synthetic methods," in Dekker Enciclopedia of Nanoscience and Nanotechnology, Taylor \& Francis, Oxford, UK, 2004.

[2] R. P. Andres, J. D. Bielefeld, J. I. Henderson, et al., "Selfassembly of a two-dimensional superlattice of molecularly linked metal clusters," Science, vol. 273, no. 5282, pp. 16901693, 1996.

[3] C. J. Zhong, J. Luo, M. M. Maye, L. Han, and N. N. Kariuki, "Nanostructured gold and alloy electrocatalysts," in Nanotechnology in Catalysis, vol. 1, pp. 222-248, Kluwer Academic/Plenum Publishers, Dordrecht, The Netherlands, 2004.

[4] E. Katz and I. Willner, "Integrated nanoparticle-biomolecule hybrid systems: synthesis, properties, and applications," Angewandte Chemie International Edition, vol. 43, no. 45, pp. 60426108, 2004.

[5] R. Turton, The Quantum Dot: A Journey into the Future of Microelectronics, Oxford University Press, New York, NY, USA, 1995.

[6] M. Brust, J. Fink, D. Bethell, D. J. Schiffrin, and C. Kiely, "Synthesis and reactions of functionalised gold nanoparticles," Journal of the Chemical Society, Chemical Communications, no. 16, pp. 1655-1656, 1995.

[7] G. Schmid, R. Pfeil, R. Boese, et al., " $\mathrm{Au}_{55}\left[\mathrm{P}\left(\mathrm{C}_{6} \mathrm{H}_{5}\right)_{3}\right]_{12} \mathrm{Cl}_{6}-\mathrm{a}$ gold cluster of unusual size," Chemische Berichte, vol. 114, no. 11, pp. 3634-3642, 1981.

[8] M. Brust, M. Walker, D. Bethell, D. J. Schiffrin, and R. Whyman, "Synthesis of thiol-derivatised gold nanoparticles in a two-phase liquid-liquid system," Journal of the Chemical Society, Chemical Communications, no. 7, pp. 801-802, 1994.

[9] M.-C. Daniel and D. Astruc, "Gold nanoparticles: assembly, supramolecular chemistry, quantum-size-related properties, and applications toward biology, catalysis, and nanotechnology," Chemical Reviews, vol. 104, no. 1, pp. 293-346, 2004.

[10] K.-S. Kim, D. Demberelnyamba, and H. Lee, "Size-selective synthesis of gold and platinum nanoparticles using novel thiol-functionalized ionic liquids," Langmuir, vol. 20, no. 3, pp. 556-560, 2004.

[11] M. Hasan, D. Bethell, and M. Brust, "The fate of sulfur-bound hydrogen on formation of self-assembled thiol monolayers on gold: ${ }^{1} \mathrm{H}$ NMR spectroscopic evidence from solutions of gold clusters," Journal of the American Chemical Society, vol. 124, no. 7, pp. 1132-1133, 2002.

[12] Y.-S. Shon, W. P. Wuelfing, and R. W. Murray, "Water-soluble, sulfonic acid-functionalized, monolayer-protected nanoparticles and an ionically conductive molten salt containing them," Langmuir, vol. 17, no. 4, pp. 1255-1261, 2001.

[13] O. Tzhayik, P. Sawant, S. Efrima, E. Kovalev, and J. T. Klug, "Xanthate capping of silver, copper, and gold colloids," Langmuir, vol. 18, no. 8, pp. 3364-3369, 2002.

[14] R. T. Tom, V. Suryanarayanan, P. G. Reddy, S. Baskaran, and T. Pradeep, "Ciprofloxacin-protected gold nanoparticles," Langmuir, vol. 20, no. 5, pp. 1909-1914, 2004.

[15] C. K. Yee, A. Ulman, J. D. Ruiz, A. Parikh, H. White, and M. Rafailovich, "Alkyl selenide- and alkyl thiolate-functionalized gold nanoparticles: chain packing and bond nature," Langmuir, vol. 19, no. 22, pp. 9450-9458, 2003.

[16] S. J. Bae, C. Lee, I. S. Choi, et al., "Adsorption of 4biphenylisocyanide on gold and silver nanoparticle surfaces: surface-enhanced raman scattering study," The Journal of Physical Chemistry B, vol. 106, no. 28, pp. 7076-7080, 2002.

[17] S. Chen and J. M. Sommers, "Alkanethiolate-protected copper nanoparticles: spectroscopy, electrochemistry, and solid-state morphological evolution," The Journal of Physical Chemistry B, vol. 105, no. 37, pp. 8816-8820, 2001.

[18] J. Yang, J. Y. Lee, T. C. Deivaraj, and H.-P. Too, “An improved procedure for preparing smaller and nearly monodispersed thiol-stabilized platinum nanoparticles," Langmuir, vol. 19, no. 24, pp. 10361-10365, 2003.

[19] I. Quiros, M. Yamada, K. Kubo, J. Mizutani, M. Kurihara, and H. Nishihara, "Preparation of alkanethiolate-protected palladium nanoparticles and their size dependence on synthetic conditions," Langmuir, vol. 18, no. 4, pp. 1413-1418, 2002.

[20] D.-H. Chen and S.-H. Wu, "Synthesis of nickel nanoparticles in water-in-oil microemulsions," Chemistry of Materials, vol. 12, no. 5, pp. 1354-1360, 2000.

[21] T. P. Ang and W. S. Chin, "Dodecanethiol-protected copper/silver bimetallic nanoclusters and their surface properties," The Journal of Physical Chemistry B, vol. 109, no. 47, pp. 22228-22236, 2005.

[22] S. D. Bunge, T. J. Boyle, and T. J. Headley, "Synthesis of coinage-metal nanoparticles from mesityl precursors," Nano Letters, vol. 3, no. 7, pp. 901-905, 2003.

[23] R. A. Salkar, P. Jeevanandam, G. Kataby, et al., "Elongated copper nanoparticles coated with a zwitterionic surfactant," The Journal of Physical Chemistry B, vol. 104, no. 5, pp. 893$897,2000$.

[24] K. J. Ziegler, R. C. Doty, K. P. Johnston, and B. A. Korgel, "Synthesis of organic monolayer-stabilized copper nanocrystals in supercritical water," Journal of the American Chemical Society, vol. 123, no. 32, pp. 7797-7803, 2001. 
[25] N. Sandhyarani and T. Pradeep, "Crystalline solids of alloy clusters," Chemistry of Materials, vol. 12, no. 6, pp. 1755-1761, 2000.

[26] J. C. Love, L. A. Estroff, J. K. Kriebel, R. G. Nuzzo, and G. M. Whitesides, "Self-assembled monolayers of thiolates on metals as a form of nanotechnology," Chemical Reviews, vol. 105, no. 4, pp. 1103-1170, 2005.

[27] H. Ahn, M. Kim, D. J. Sandman, and J. E. Whitten, "Selfassembled monolayers of $\omega$-(3-thienyl)alkanethiols on gold," Langmuir, vol. 19, no. 13, pp. 5303-5310, 2003.

[28] P. Bäuerle, F. Würthner, and S. Heid, "Facile synthesis of 3-( $\omega$ haloalkyl)thiophenes as key building blocks for functionalized thiophenes and polythiophenes," Angewandte Chemie International Edition, vol. 29, no. 4, pp. 419-420, 1990.

[29] A. Ulman, An Introduction to Ultrathin Organic Films, Academic Press, New York, NY, USA, 1991.

[30] M. D. Porter, T. B. Bright, D. L. Allara, and C. E. D. Chidsey, "Spontaneously organized molecular assemblies. 4. Structural characterization of $n$-alkyl thiol monolayers on gold by optical ellipsometry, infrared spectroscopy, and electrochemistry," Journal of the American Chemical Society, vol. 109, no. 12, pp. 3559-3568, 1987.

[31] R. G. Nuzzo, L. H. Dubois, and D. L. Allara, "Fundamental studies of microscopic wetting on organic surfaces. 1. Formation and structural characterization of a self-consistent series of polyfunctional organic monolayers," Journal of the American Chemical Society, vol. 112, no. 2, pp. 558-569, 1990.

[32] T. P. Ang, T. S. A. Wee, and W. S. Chin, "Three-dimensional self-assembled monolayer (3D SAM) of $n$-alkanethiols on copper nanoclusters," The Journal of Physical Chemistry B, vol. 108, no. 30, pp. 11001-11010, 2004.

[33] N. Sandhyarani and T. Pradeep, "An investigation of the structure and properties of layered copper thiolates," Journal of Materials Chemistry, vol. 11, no. 4, pp. 1294-1299, 2001.

[34] J. A. Creighton and D. G. Eadon, "Ultraviolet-visible absorption spectra of the colloidal metallic elements," Journal of the Chemical Society, Faraday Transactions, vol. 87, no. 24, pp. 3881-3891, 1991.

[35] G. Mie, "Beiträge zur Optik trüber Medien, speziell kolloidaler Metallösungen," Annalen der Physik, vol. 330, no. 3, pp. 377445, 1908.

[36] C. F. Bohren and D. R. Huffman, Absorption and Scattering of Light by Small Particles, John Wiley \& Sons, New York, NY, USA, 1983.

[37] A. Pal, S. Shah, and S. Devi, "Synthesis of Au, Ag and Au-Ag alloy nanoparticles in aqueous polymer solution," Colloids and Surfaces A, vol. 302, no. 1-3, pp. 51-57, 2007.

[38] Z. Zhang, F. Wang, F. Chen, and G. Shi, "Preparation of polythiophene coated gold nanoparticles," Materials Letters, vol. 60, no. 8, pp. 1039-1042, 2006. 

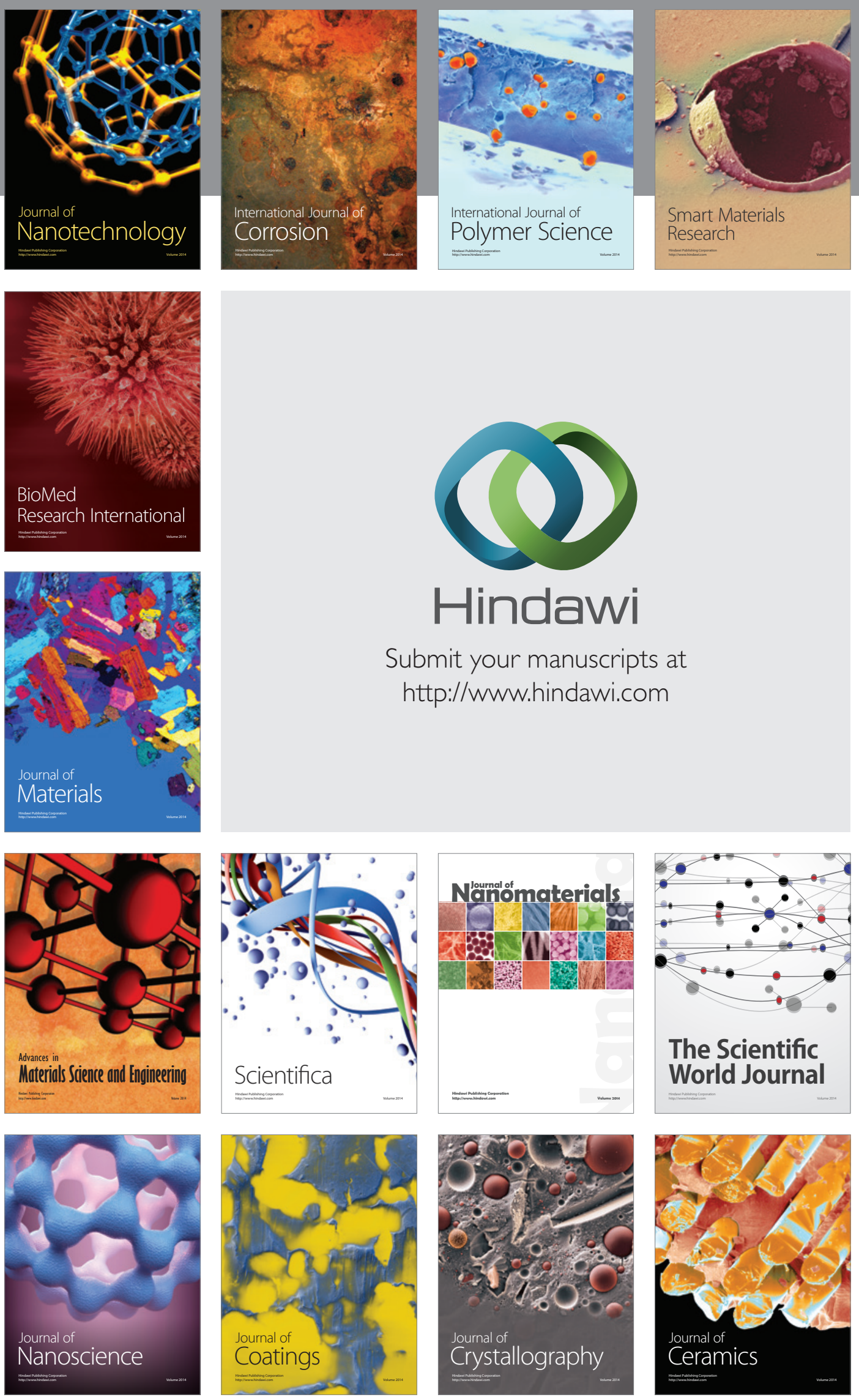

The Scientific World Journal

Submit your manuscripts at

http://www.hindawi.com

\section{World Journal}

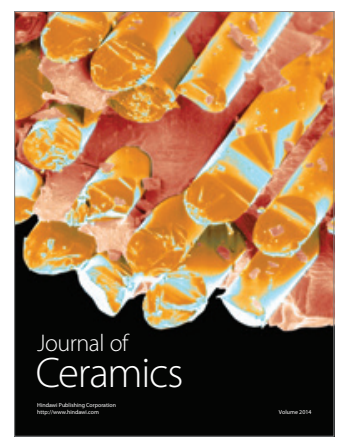

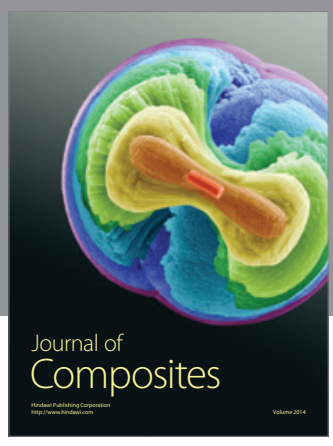
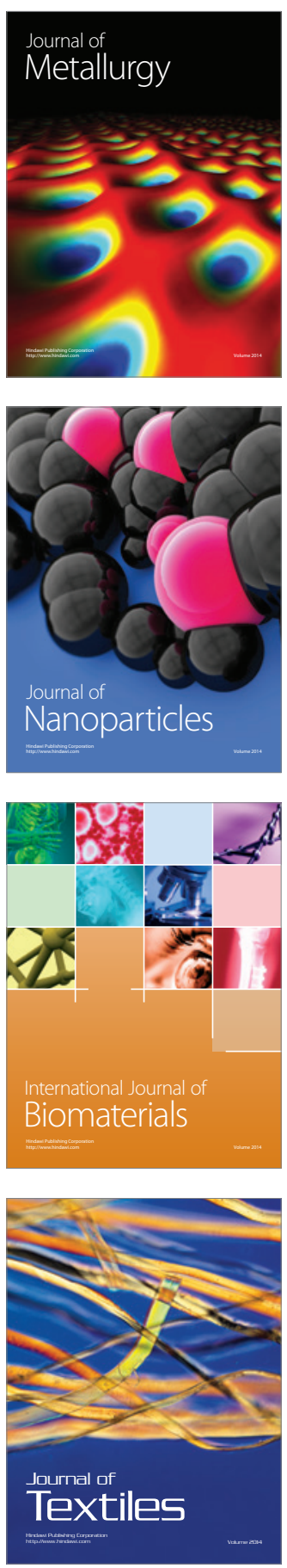